\title{
Spectrum of Congenital Abdominal Wall Defects in Neonates in a Teaching Hospital in Enugu, Nigeria
}

Chukwubuike Kevin Emeka

Pediatric Surgery Unit, Department of Surgery, Enugu State University Teaching Hospital, Enugu, Nigeria.

*Corresponding Author: Chukwubuike Kevin Emeka, Department of Surgery, Enugu State University Teaching Hospital, Enugu, Nigeria.

Received date: January 31, 2020: Accepted date: February 18, 2020: Published date: February 22, 2020

Citation: Chukwubuike K Emeka. (2021) Spectrum of Congenital Abdominal Wall Defects in Neonates in a Teaching Hospital in Enugu, Nigeria. Journal of Clinical Surgery and Research. 1(1) DOI: 10.31579/2768-2757/004

Copyright: (92021 Chukwubuike Kevin Emeka, This is an open-access article distributed under the terms of the Creative Commons Attribution License, which permits unrestricted use, distribution, and reproduction in any medium, provided the original author and source are credited.

\section{Abstract}

Objective: To evaluate our experience on the pattern and treatment outcome of neonates who presented with congenital abdominal wall defects (CAWD) in a teaching hospital in Enugu, Nigeria.

Methodology: This was a retrospective study of neonates who presented with abdominal wall defect of congenital origin between January 2014 and December 2018 at the pediatric surgery unit of Enugu State University Teaching Hospital (ESUTH) Enugu, Nigeria.

Results: A total of 236,231 neonates were seen during the study period. Out of this number, 48 neonates had CAWD. This gave a prevalence of $0.02 \%$ or 2 babies per 10,000 births. There was male predominance and majority of the neonates were delivered preterm through the vaginal route. Omphalocele and gastroschisis were the most common CAWD and about 50\% of the CAWD were diagnosed prenatally through maternal ultrasound. There was a low incidence of associated anomalies and only one-tenth of the mothers gave a history of a possible risk factor. Treatment of CAWD depended on the specific anomaly and sepsis was the most common post-operative complication. Mortality occurred in $8(16.7 \%)$ neonates.

Conclusion: Omphalocele and gastroschisis were the most common types of CAWD recorded in the present study. Most of the neonates were delivered vaginally as preterm babies. Treatment was based on the type of CAWD and majority of the neonates survived.

Keywords: abdominal wall; congenital; defect; observational; spectrum

\section{Introduction}

Congenital abdominal wall defects (CAWD) refer to a spectrum of malformations of the abdominal wall that result from abnormal embryogenesis. It ranges from omphalocele to lethal limb-body wall syndrome [1]. CAWD is one of the commonest structural developmental defects in man [2]. CAWD is classified into omphalocele, gastroschisis, prune belly syndrome and limb-body wall syndrome. In omphalocele, there is herniation of the abdominal viscera into the base of the umbilical cord. In gastroschisis, there is a defect lateral to the umbilicus with evisceration of the intestine into the amniotic cavity in utero. Prune-belly syndrome is an anomaly in which the abdominal wall is thin and lax revealing the intestinal pattern [3]. Limb-body wall syndrome, also known as body stalk anomaly, is the rarest, most severe and invariably lethal abdominal wall defect. It is a severe defect in which the abdominal wall does not develop and thus the peritoneal cavity is open to the extraembryonic coelom and the fetus is attached to the placenta [4]. The incidence of CAWD varies widely depending on the rarity of the condition. For instance, the birth prevalence of gastroschisis is 1 in 10 , 000 births and omphalocele 2.5 in 10,000 births [5]. Reports from United States suggest that the rate of gastroschisis has increased as much a 10fold over the past decade. The increased detection and incidence of gastroschisis may be due to increased use of prenatal ultrasonography [6]. Diagnosis of CAWD is usually clinical and initial management consists of covering the eviscerated bowel using warm laparotomy pads to prevent heat loss and bowel desiccation. There is paucity of data on CAWD in Enugu, Nigeria, hence, the need for this study. The aim of this study was to evaluate our experience on the pattern and treatment of neonates who presented with CAWD in a teaching hospital in Enugu, Nigeria.

\section{Methods}

This was a retrospective study of neonates who presented with abdominal wall defect of congenital origin between January 2014 and December 2018 at the pediatric surgery unit of Enugu State University Teaching Hospital (ESUTH) Enugu, Nigeria. ESUTH is a tertiary hospital located in Enugu, South East Nigeria. The hospital serves the whole of Enugu State, which according to the 2016 estimates of the National Population Commission and Nigerian National Bureau of Statistics, has a population of about 4 million people and a population density of $616.0 / \mathrm{km}^{2}$. The hospital also receives referrals from its neighboring states. Only neonates with clinically obvious and observable CAWD were enrolled into the study. Diagnosis of CAWD was by clinical examination. Investigations such as abdominal radiography and ultrasonography were not done. Both 
live babies and stillbirths seen during the study period were recruited into the study. Patients with incomplete medical records and those who are older than one month of age were excluded from the study. Information was extracted from case notes, operation notes, operation register, and admission-discharge records. The information extracted included age of the neonate at presentation, gender, maternal age, gestational age of the pregnancy before delivery, weight of the neonate, mode of delivery, type of CAWD, modality of treatment of CAWD, complications of treatment, treatment outcome. Baby's birth weight greater or equal to 2.5 kilograms $(\mathrm{kg})$ were considered to be normal while birth weight less than $2.5 \mathrm{~kg}$ were considered as low birth weight. Babies born at less than 37 completed weeks, calculated from the first day of last menstrual period, were considered preterm while babies born at or after 37 completed weeks were considered term. Ethical approval was obtained from the Ethics and Research committee of ESUTH. Statistical Package for Social Science (SPSS) version 21, Data was expressed as percentage, median, mean and range.

\section{Results}

\section{Patients' demographics}

A total of 236,231 neonates were seen during the study period. Out of this number, 48 neonates had CAWD. This gives a prevalence of $0.02 \%$ or 2 babies per 10,000 births. Among all congenital anomalies, CAWD accounted for $10 \%$ in the current series. Demographic characteristics of the patients are depicted in Table 1 .

\begin{tabular}{|c|c|}
\hline Gender & \\
\hline Male & $36(75 \%)$ \\
\hline Female & $12(25 \%)$ \\
\hline Mean postnatal age at presentation & 12 hours (1-48 hours) \\
\hline Gestational age at birth & $17(35.4 \%)$ \\
\hline Term & $31(64.6 \%)$ \\
\hline Preterm & $29(60.4 \%)$ \\
\hline Weight at birth & $19(39.6 \%)$ \\
\hline Less than 2.5 kilograms & \\
\hline 2.5 kilograms and above & $25(52 \%)$ \\
\hline Maternal age & $23(48 \%)$ \\
\hline 35 years and younger & \\
\hline Above 35 years & \\
\hline Mode of delivery & \\
\hline Vaginal & \\
\hline Caesarian section & \\
\hline
\end{tabular}

Table 1: Demographic characteristics of the patients

\section{Types of CAWD in the neonates}

The CAWD seen in the studied neonates are shown in Table 2.

\begin{tabular}{|c|c|}
\hline Congenital Abdominal Wall Defects & Number of neonates (\%) \\
\hline Omphalocele & $31(64.5)$ \\
\hline Unruptured & $22(45.8)$ \\
\hline Ruptured & $9(18.7)$ \\
\hline Gastroschisis & $13(27.1)$ \\
\hline Prune-belly syndrome & $2(4.2)$ \\
\hline Bladder exstrophy & $1(2.1)$ \\
\hline Cloacal exstrophy & $1(2.1)$ \\
\hline
\end{tabular}

Table 2: Spectrum of the CAWD seen in the studied neonates

\section{Prenatal diagnosis of CAWD}

Forty-two $(87.5 \%)$ mothers whose babies had CAWD were booked cases while $6(12.5 \%)$ mothers were unbooked cases. Twenty-two (45.8\%) patients had an ultrasound diagnosis of CAWD through prenatal maternal ultrasound scan. Five $(10.4 \%)$ of the mothers had a previous history of having a baby with CAWD.
One $(2.1 \%)$ neonate with omphalocele had spina bifida cystica. One $(2.1 \%)$ neonate with gastroschisis had an associated intestinal atresia. No other observable birth defects were noticed in any of the patients. Karyotyping and investigations were not done.

\section{Possible maternal risk factors}

\section{Associated anomalies}


Ten $(20.8 \%)$ mothers were either diabetic, hypertensive or had a history of ingestion of herbal concoction in the first trimester of pregnancy. There was a history of febrile illness in early pregnancy in $3(6.3 \%)$ mothers.

\section{Modalities of treatment}

\section{Unruptured omphalocele}

Neonates with unruptured omphalocele were treated by "paint and wait". In paint and wait, the omphalocele was dressed with epithelizing agent such as $1 \%$ silver sulphadiazine. The principle in this modality of treatment is to convert the omphalocele to a ventral hernia which is repaired operatively later in childhood.

\section{Ruptured omphalocele}

Treatment entails operative reduction of the eviscerated bowel back into the peritoneal cavity and repair of the abdominal wall is done. Where there is loss of domain, a silo is applied and gradual reduction of the eviscerated bowel is performed.

\section{Gastroschisis}

The same treatment protocol practiced in ruptured omphalocele is offered to babies with gastroschisis.

\section{Prune-belly syndrome}

Initial care of neonates with prune-belly syndrome depends on the findings on initial evaluation. Those with urethral obstruction benefit from urinary diversion such as vesicostomy. Other treatments such as orchidopexy, abdominal wall reconstruction and ureteric replantations are performed later in childhood.

\section{Complications of treatment}

Three $(6.3 \%)$ patients developed anesthetic complications in the form of atelectasis and drug reaction. Two (4.2\%) patients with unruptured omphalocele had an accidental rupture of the omphalocele sac during the dressing process. Six (12.5\%) patients with gastroschisis had severe sepsis from infection of the applied silo. Intestinal obstruction occurred in one $(2.1 \%)$ patient due to adhesion between the bowel and the omphalocele membrane.

\section{Treatment outcome}

Forty $(83.3 \%)$ patients recovered and were discharged home. Eight $(16.7 \%)$ patients expired due to overwhelming sepsis from infected silo.

\section{Discussion}

CAWD represents a range of congenital anomalies affecting the abdominal wall. Although CAWD affect the abdominal wall, they differ widely in their pathogenesis, genetic, presentation, associated anomalies and management [1]. Newborns with CAWD were first described in the literature as early as the first century AD by a Roman physician, Aulus Cornelius Celsus [7]. Schuster was the first to describe the use of a silastic silo to gradually reduce the abdominal contents back into the abdomen [7]. The clinical acumen of the physician in the evaluation and diagnosis of CAWD is most relevant since the diagnosis of CAWD is usually made clinically.

The prevalence of 2 cases per 10,000 births recorded in the present study is comparable to the report of Rankin et al [8]. However, Boyd et al recorded a prevalence of 6 cases per 10,000 births [9]. The reason for the difference in prevalence may be due to the cohort of patients (live births/stillbirths, neonates/infants/older children) enrolled into a particular study. CAWD accounted for one-tenth of all congenital anomalies in the current study. This is similar to the report of one study from Enugu, Nigeria [10]. A series from India reported gastrointestinal congenital anomalies as the most common congenital anomaly [11]. The pattern of congenital anomalies may vary from one country to another and from time to time [12].

There is male predominance in the current study. This is consistent with the report of other studies [13, 14]. Howbeit, one study from Ilorin, Nigeria reported a slight female predominance [15]. The reason for the gender difference is not known. The mean age of our patients is at variance to the findings of Abdur-Rahman et al [15]. The type of CAWD may determine the age at presentation. For instance, neonates with gastroschisis may present early due to frightening sight of the exposed bowel to the parents. About two-thirds of our patients were preterm babies. A study from Manchester, United Kingdom reported that CAWD is associated with prematurity and low birth weight [16]. Preterm delivery is more frequent in neonates with gastroschisis [7]. Majority of our studied neonates with CAWD weighed less than $2.5 \mathrm{~kg}$ at birth. Stoll et al reported that the weight, length and head circumference of neonates with CAWD were less than those of controls [17]. The low birth weight is more common in neonates with gastroschisis and has been associated with increased risk of septic complications [18]. Young maternal age has been found as a risk factor for gastroschisis with a sevenfold incidence among teenage mothers while omphalocele is more associated with older maternal age $[1,19]$. Vaginal delivery is the predominant method of delivery in the index study. Segel et al in their study found no evidence to support cesarean delivery in babies with CAWD [20]. Vaginal delivery is the preferred mode of delivery unless an indication for cesarean delivery is present for obstetric reasons or fetal distress [1]. A meta-analysis on the mode of delivery of babies with CAWD reported no difference in overall mortality, incidence of necrotizing enterocolitis, sepsis, time to full feeds, or duration of hospital stay [21].

Omphalocele accounted for about two-thirds of the CAWD seen in the present study and was the most common. Other researchers also reported omphalocele as the most common abdominal defect [22, 23]. Omphalocele is a midline abdominal wall defect in which a thin membrane surrounds the protruding organs that can include small intestine, liver, bladder, and stomach [24]. In females, the uterus and ovaries may be part of the protruding organs [24]. Omphalocele results from failure of return of the intestinal loops into the body cavity during the $10^{\text {th }}$ week of gestation. Gastroschisis is a CAWD in which there is a herniation of the bowel (without a membranous covering) through a defect located 1 to $2 \mathrm{~cm}$ to the side of the umbilicus. Gastroschisis results from early compromise of the right umbilical vein or the omphalomesenteric artery, which causes mesodermal and endodermal ischemic injury to the abdominal wall. Gastroschisis is the second most common CAWD in the current series. However, there are reports of rising incidence of gastroschisis [25, 26]. Prune-belly syndrome, also known as Eagle-Barrett syndrome, is a rare multisystem disorder characterized by partial or complete absence of the abdominal muscles, undescended testis and urinary tract anomalies [27]. The anomalies in Prune belly syndrome ranges from mild to severe. Bladder and cloacal exstrophy are complex anomalies of the abdominal wall involving the genitourinary system and the hind gut. They are the most severe in the spectrum of extrophic anomalies of the anterior abdominal wall. Other abdominal wall defects such as limb-body wall syndrome and pentalogy of Cantrel were not seen during the study period.

Prenatal diagnosis of congenital anomalies is a growing trend in clinical radiology. The widespread use of fetal ultrasound in routine antenatal care allows CAWD to be identified. Prenatal ultrasonography is the key imaging modality because of its non-invasive nature and absence of irradiations. About half of our patients had a prenatal diagnosis of their CAWD. Chen et al reported a detection rate of $66.7 \%$ for omphalocele and gastroschisis [28]. The detection rate of CAWD prenatally may depend on the experience, expertise and the trimester when the maternal ultrasound was performed. Most cases of CAWD are sporadic. However, 
in the present study, one-tenth of the mothers whose babies had CAWD had previously had a baby with CAWD. Familial cases of abdominal wall defects have been reported [29].

Omphalocele is often associated with chromosomal and other congenital anomalies while gastroschisis is less frequently associated with other anomalies [30]. In the index study, one patient in each group had an associated anomaly. One study from Texas birth defect registry reported intestinal atresia as the most common associated anomaly in gastroschisis, similar to our finding in the present study [31]. Overall, there were more associated anomalies in omphalocele than in gastroschisis [31].

One-fifth of our patients had a history of ingestion of herbal concoction in early pregnancy or hypertensives or diabetics. Other researches also mentioned the association between CAWD and the above mentioned risk factors [30]. It is worthy to note that in most cases of CAWD, no possible risk factor can be found.

The treatment of CAWD is dependent on the specific defect. Generally, initial care of the neonate entails prevention of hypothermia through provision of warmth, intravenous dextrose containing fluids, intravenous antibiotics, passage of nasogastric tube to decompress the upper gastrointestinal tract and urethral catheter to monitor urine output which equates with tissue perfusion. For unruptured omphalocele, non-operative treatment which involves painting the omphalocele with epithelizing agent is the most common method of treatment in our setting. Several epithelizing agents such as silver sulphadiazine, povidone iodine, and honey are used. A study from Ile-Ife, Nigeria also used similar agents for non-operative treatment of omphalocele [32]. The disadvantages of nonoperative treatment include long duration of hospital stay and the attendant cost to the parents. In ruptured omphalocele and gastroschisis, an operative procedure is required to reduce the bowel and repair the abdominal wall. A silo is applied for gradual reduction of the eviscerated bowel. Except relief of urethral obstruction (if there is any), no immediate treatment is offered to neonates with Prune-belly syndrome.

Sepsis resulting from silo application in neonates with gastroschisis was the most common complication recorded in the current series. The immature immune status of the neonate and foreign body (silo) reaction may be responsible for the high infection rate. The high infection rates experienced with silo has been reported by other practitioners [33]. In low income like Nigeria, silo is always improvised using surgical gloves and drainage bags.

One-third of our patients expired due to overwhelming sepsis. This mortality rate in the index study is comparable to the reports of Mayer et al [34]. However, Anyanwu et al reported a mortality of $87 \%$ [35]. They documented that this high mortality resulted from hypothermia and sepsis that were present in the neonates before presentation to the hospital. Mortality following treatment of CAWD may depend on the specific type of CAWD, associated congenital anomalies and clinical condition of the neonates at presentation [36].

\section{Limitations of the study}

1. Small number of neonates with CAWD. A larger number would have availed better analysis

2. This is a hospital based observational study. Neonates with CAWD delivered and treated outside the teaching hospital were not captured. Investigations such as karyotyping and Echocardiography were not done.

\section{Recommendation}

Prenatal ultrasound should be encouraged in all pregnant women for early detection of CAWD. Delivery should be conducted in a hospital with pediatric surgery services for prompt and adequate care of neonates with CAWD.

\section{Conclusion}

CAWD is a spectrum of anomalies affecting the anterior abdominal wall and has a prevalence of 2 per 10,000 births. Omphalocele and gastroschisis are the most common types. Majority of our patients were preterms and were delivered vaginally. Half of the CAWD were diagnosed prenatally and there is low incidence of associated anomalies in the present study. Treatment depended on the type of CAWD and mortality rate was $16.7 \%$.

\section{References}

1. Mansfield SA, Jancelewicz T. (2019) Ventral Abdominal Wall Defects. Pediatr Rev. 40(12): 627-635.

2. Nyberg DA, Mack LA. Abdominal wall defects. In: Nyberg DA, Mahony BS, Pretorius DH (eds). (1990) Diagnostic ultrasound of fetal abnormalities: text and atlas, St Louis, MO, Mosby-Year Book, 395-432.

3. Agarwal R. (2005) Prenatal diagnosis of anterior abdominal wall defects: Pictorial essay. Indian J Radiol Imaging. 15: 361372.

4. Daskalakis G, Pilalis A, Papadopoulos D, Antsaklis A. (2003) Body Stalk Anomaly Diagnosed in the $2^{\text {nd }}$ Trimester. Fetal Diag Ther. 18: 342-344.

5. Weber TR, Au-Fliegner M, Downard CD, Fishman SJ. (2002) Abdominal wall defects. Curr Opin Pediatr. 14(4): 491-497.

6. Alvarez SM, Burd RS. (2007) Increasing prevalence of gastroschisis repairs in the United States: 1996-2003. J Pediatr Surg. 42(6): 943-946.

7. Christison-Lagay ER, Kelleher CM, Langer JC. (2011) Neonatal abdominal wall defects. Seminars in Fetal and Neonatal Medicine. 16: 164-172.

8. Rankin J, Dillon E, Wright C. (1999) Congenital abdominal wall defects in the North of England, 1986-1996: occurrence and outcome. 19(7): 662-668.

9. Boyd PA. (2011) Eurocat report 9: Surveillance of congenital anomalies in Europe. 1980-2008. Birth Defects Res A Clin Mol Teratol. 91(suppl 1).

10. Chukwubuike KE, Ozor I, Enyi N. (2020) Prevalence and pattern of birth defects in the two tertiary hospitals in Enugu, South East Nigeria: A hospital-based observational study. Afr J Paediatr Surg. 17(3 \& 4): 85-89.

11. Suguna Bai NS, Mascarene M, Syamalan K, Nair PM. (1982) An etiological study of congenital malformation in the newborn. Indian Pediatr. 19: 1003-1007.

12. Singh K, Krishnamurthy K, Greaves C, Kandamaran L, Nielsen AL, Kumar A. (2014) Major Congenital Malformations in barbados: The prevalence, the pattern and the resulting morbidity and mortality. ISRN Obstet Gynecol.

13. Schmedding A, Wittekind B, Salzmann-Manrique E, Schloesser R, Rolle U. (2020) Decentralized surgery of abdominal wall defects in Germany. Pediatr Surg Int. 36(5): 569-578.

14. Beam K, Wojcik MH, Agrawal PB, Smithers C, Estroff J. (2020) Prenatal Diagnosis of a Ventral Abdominal Wall Defect. Neoreviews. 21(4): 286-292.

15. Abdur-Rahman LO, Abdulrasheed NA, Adeniran JO. (2011) Challenges and outcomes of management of anterior abdominal wall defects in a Nigerian tertiary hospital. Afr J Paediatr Surg. 8(2): 159-163.

16. Poddar R, Hartley L. (2009) Exomphalus and gastroschisis, Continuing Education in Anaesthesia Critical Care \& Pain.; 9(2): 48-51.

17. Stoll C, Alembik Y, Dott B, Roth MP. (2001) Risk factors in congenital abdominal wall defects (omphalocele and 
gastroschisis): a study in a series of 265,858 consecutive births. Ann Genet. 44(4): 201-208.

18. Brandtberg A, Blaas HGK, Salvesen KA, Haugen SE, Eik-nes SH. (2004) Surveillance and outcome of fetuses with gastroschisis. Ultrasound in Obstetrics and Gynecology. 23(1):1-13.

19. Mac Bird T, Robbins JM, Druschel C, Cleves MA, Yang S, Hobbs CA. (2009) Demographic and environmental risk factors for gastroschisis and omphalocele in National Birth Defects Prevention Study. Demographic and environmental risk factors for gastroschisis and omphalocele in the National Birth Defects Prevention Study. J Pediatr Surg. 44(8): 1546-1551.

20. Segel SY, Marder SJ, Parry S, Macones GA. (2001) Fetal abdominal wall defects and mode of delivery: a systemic review. Obstet Gynecol. 98(5 Pt 1): 867-873.

21. Kirollos DW, Abdel-Latif ME. (2018) Mode of delivery and outcomes of infants with gastroschisis: a meta-analysis of observational studies. Arch Dis Child Fetal Neonatal Ed. 103(4): 355-363.

22. Corey KM, Hornik CP, Laughon MM, McHutchison K, Clark RH, Smith PB. (2014) Frequency of anomalies and hospital outcomes in infants with gastroschisis and omphalocele. Early Hum Dev. 90(8): 421-424.

23. Singh K, Kumar A. (2017) Anterior Abdominal Wall Defects, Diaphragmatic Hernia, and Other Major Congenital Malformations of the Musculoskeletal System in Barbados, 1993-2012. J Pediatr Genet. 6(2): 92-97.

24. Frolov P, Alali J, Klein MD. (2010) Clincical risk factors for gastroschisis and omphalocele in humans: a review of the literature. Pediatr Surg Int. 26(12): 1135-1148.

25. Kilby MD. (2006) The incidence of gastroschisis. BMJ. 332(7536): 250-251.

26. Holland AJ, Walker K, Badawi N. (2010) Gastroschisis: an update. Pediatr Surg Int. 26(9): 871-878.
27. Arlen AM, Nawaf C, Kirsch AJ. (2019) Prune belly syndrome: current perspectives. Pediatric Health Med Ther. 10: 75-81.

28. Chen CP, Liu FF, Jan SW, Sheu JC, Huang SH, Lan CC. (1996) Prenatal diagnosis and perinatal aspects of abdominal wall defects. Am J Perinatol. 13(6): 355-361.

29. Hershey DW, Haesslein HC, Marr CC, Adkins JC. (1989) Familial abdominal wall defects. Am J Med Genet. 34(2): 174176.

30. Hwang PJ, Kousseff BG. (2004) Omphalocele and gastroschisis: an 18-year review study. Genet Med. 6(4): 232236.

31. Benjamin B, Wilson GN. (2014) Anomalies associated with gastroschisis and omphalocele: analysis of 2825 cases from the Texas Birth Defects Registry. J Pediatr Surg. 49(4): 514-519.

32. Talabi AO, Sowande OA, Adejuyigbe O. (2020) Challenges in the management of omphalocele in Ile-Ife. J Clin Neonatol. 9: 280-285.

33. Okoro PE, Ngaikedi C. (2020) Outcome of management of gastroschisis: comparison of improvised surgical silo and extended right hemicolectomy. Ann Pediatr Surg. 16(5).

34. Mayer T, Black R, Matlat ME, Johnson DG. (1980) Gastroschisis and omphalocele. An eight-year review. Ann Surg. 192(6): 783-787.

35. Anyanwu LJC, Ade-Ajayi N, Rolle U. (2020) Major abdominal wall defects in the low- and middle- income setting: current status and priorities. Pediatr Surg Int. 36: 579-590.

36. Klein MD, Kosloske AM, Hertzler JH. (1981) Congenital defects of the abdominal wall. A review of the experience in New Mexico. JAMA. 24: 245(16): 1643-1646. 